\title{
New aspect of morphometric study of the superior peroneal retinaculum: pertinent data for surgical repair and reconstruction
}

\author{
P. Dangintawat ${ }^{1}$, J. Apinun² ${ }^{2}$ T. Huanmanop ${ }^{3}$, S. Agthong ${ }^{3}$, V. Chentanez ${ }^{3}$ \\ ${ }^{1}$ Medical Science Programme, Faculty of Medicine, King Chulalongkorn Memorial Hospital, \\ Chulalongkorn University, Bangkok, Thailand \\ 2Department of Orthopaedics, Faculty of Medicine, King Chulalongkorn Memorial Hospital, \\ Chulalongkorn University, Bangkok, Thailand \\ ${ }^{3}$ Department of Anatomy, Faculty of Medicine, King Chulalongkorn Memorial Hospital, \\ Chulalongkorn University, Bangkok, Thailand
}

[Received: 26 September 2019; Accepted: 29 October 2019]

Background: This study was conducted to investigate characteristics, attachments and morphometric parameters of the superior peroneal retinaculum (SPR).

Materials and methods: Morphology and morphometric details including width, length, thickness and angle of alignment of SPR in 109 embalmed cadaveric legs were investigated. The occurrence of peroneal tendon tear was also noted.

Results: Most of SPR originated from the fibrocartilaginous ridge of the lateral malleolus. The SPR might be a single band or split into proximal and distal bands inserted on the posterior intermuscular septum and lateral wall of calcaneus, respectively. Based on the characteristics and insertion patterns, the SPR could be divided into three types: type I (double band with subtype la and Ib), type II (single band) and type III (single band) with the prevalence of $56.88 \%(12.84 \%$, $44.04 \%), 1.83 \%$, and $41.28 \%$, respectively. The average coordinate ( $X, Y$ axis) of the midpoint of width at origin measured from the tip of fibula in all types was $7.26 \pm 3.15$ and $10.45 \pm 4.52 \mathrm{~mm}$. The average coordinate of the midpoint at insertion on the posterior intermuscular septum was $24.06 \pm 4.94$ and $13.35 \pm$ \pm 5.18 , and those inserted on the lateral wall of calcaneus was $21.45 \pm 7.88$ and $13.59 \pm 6.73 \mathrm{~mm}$. Prevalence of peroneus brevis tendon tear was $12.84 \%$ (14 cases) and was associated with SPR type Ib with statistical significance.

Conclusions: Precise information of the characteristics, morphometric data and coordinates of attachment sites of SPR are essential for surgical procedures and reconstruction. (Folia Morphol 2020; 79, 3: 594-603)

Key words: morphometric data, peroneal tendon tear, reconstruction, superior peroneal retinaculum

\section{INTRODUCTION}

The superior peroneal retinaculum (SPR) is the primary stabilizer of the peroneal tendons to fit in their alignment at distal fibular level $[2,6]$. The space beneath the SPR is called the superior peroneal tunnel (SP tunnel) [2]. Contents of SP tunnel are peroneus brevis (PB) and peroneus longus (PL) tendons. Additional contents of the SP tunnel including peroneus quartus and unusual

Address for correspondence: V. Chentanez, MD, PhD, Department of Anatomy, Faculty of Medicine, King Chulalongkorn Memorial Hospital, Chulalongkorn University, Bangkok, Thailand, tel: +66-860701084, e-mail: fmedvct@gmail.com 


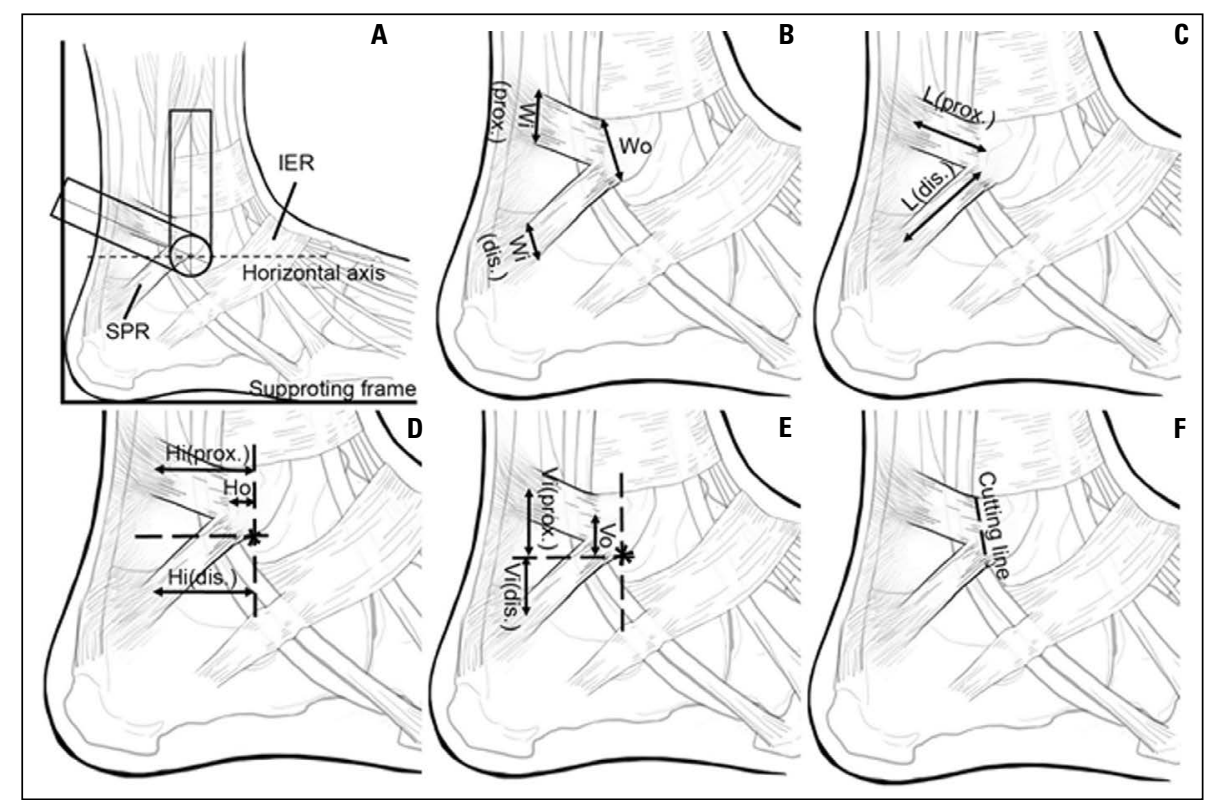

Figure 1. Illustration showing ankle supporting frame to maintain the foot in neutral position and measurement of all parameters in this position; A. Angle of the superior peroneal retinaculum (SPR) to the horizontal axis; B. The width at the origin and insertion; C. The length of the SPR; D. The horizontal distance from mid-point of SPR origin and insertion to tip of fibula $\left({ }^{*}\right)$; E. The vertical distance from mid-point of SPR origin and insertion to tip of fibula $\left({ }^{*}\right)$; F. The cutting line; Wo(prox.) — width at origin of proximal band; Wi(prox.) - width at the insertion of proximal band; Wi(dis.) — width at the insertion of distal band; Ho — horizontal distance from mid-point of origin to tip of fibula; Hi(prox.) — horizontal distance from mid-point of insertion of proximal band to tip of fibula; Hi(dis.) - horizontal distance from mid-point of insertion of distal band to tip of fibula; L(prox.) — length of the SPR proximal band; L(dis.) — length of the SPR distal band; IER — inferior extensor retinaculum.

accessory peroneal muscle were reported [1, 24]. Insufficiency of SPR was claimed to be an associated factor related to peroneal tendon disorders $[8,17,23]$. This pathology caused disabilities in walking, running and sport performances. The anatomic descriptions of SPR are extremely variable in width, thickness and their patterns of insertion $[6,18]$. Conservative treatments might not be able to prevent recurrent episodes of dislocation/subluxation of peroneal tendon $[13,18,25]$. Therefore, surgical treatment is required after unsuccessful conservative treatments [19, 22, 23]. Nowadays, several surgical procedures have been described $[4,10]$. Maffulli et al. [13] suggested that the key to successful treatment of peroneal tendon dislocation and prevention of recurrent symptom were the reattachment of SPR to its anatomical position [13]. However, knowledge of the precise area for SPR reattachment is still lacking. Therefore, the authors conducted this study to investigate the characteristics, the attachments, the morphometric parameters of SPR including width, length, thickness and angle of alignment. The distance from the attachment to inferior tip of fibula in $X$ and $Y$ axis was measured in order to locate the precise area of attachment. The presence of peroneal tendon tear was also noted. Comparisons of these parameters between genders and sides were determined.

\section{MATERIALS AND METHODS}

Formaldehyde-embalmed cadaveric legs with age range of 34-94 years (55 males and 54 females) from the Department of Anatomy, Faculty of Medicine, Chulalongkorn University were investigated. Lower extremities with injury and foot deformities were excluded. All cadaveric legs were dissected and evaluated in prone position. The skin and subcutaneous tissue were removed. Characteristics and attachments of the SPR were identified. The Achilles tendon was released and adjusted to neutral position by a supporting frame (Fig. 1A). The standardised digital Vernier calliper (GuangLu ${ }^{\circledR} 0-100 \mathrm{~mm}$; range $100 \mathrm{~mm}$, resolution $0.01 \mathrm{~mm}$ ) was used to measure each parameter. Width of SPR was measured both in origin at lateral malleolus (Wo) and at insertion (Wi) (Fig. 1B). Horizontal and vertical distances from mid-point of origin and insertion to the inferior tip of fibula were measured from $X$ and $Y$ axis (Fig. 1D, E). Length of the SPR band was also measured (Fig. 1C). The angle of the alignment of the SPR to the horizontal axis was evaluated by standard goniometer (BASELINE ${ }^{\text {TMce) }}$ (Fig. 1A). The axis of rotation was the inferior tip of fibula. The origin of SPR was cut (Fig. 1F) and its thickness was measured at its middle part. The presence of the 

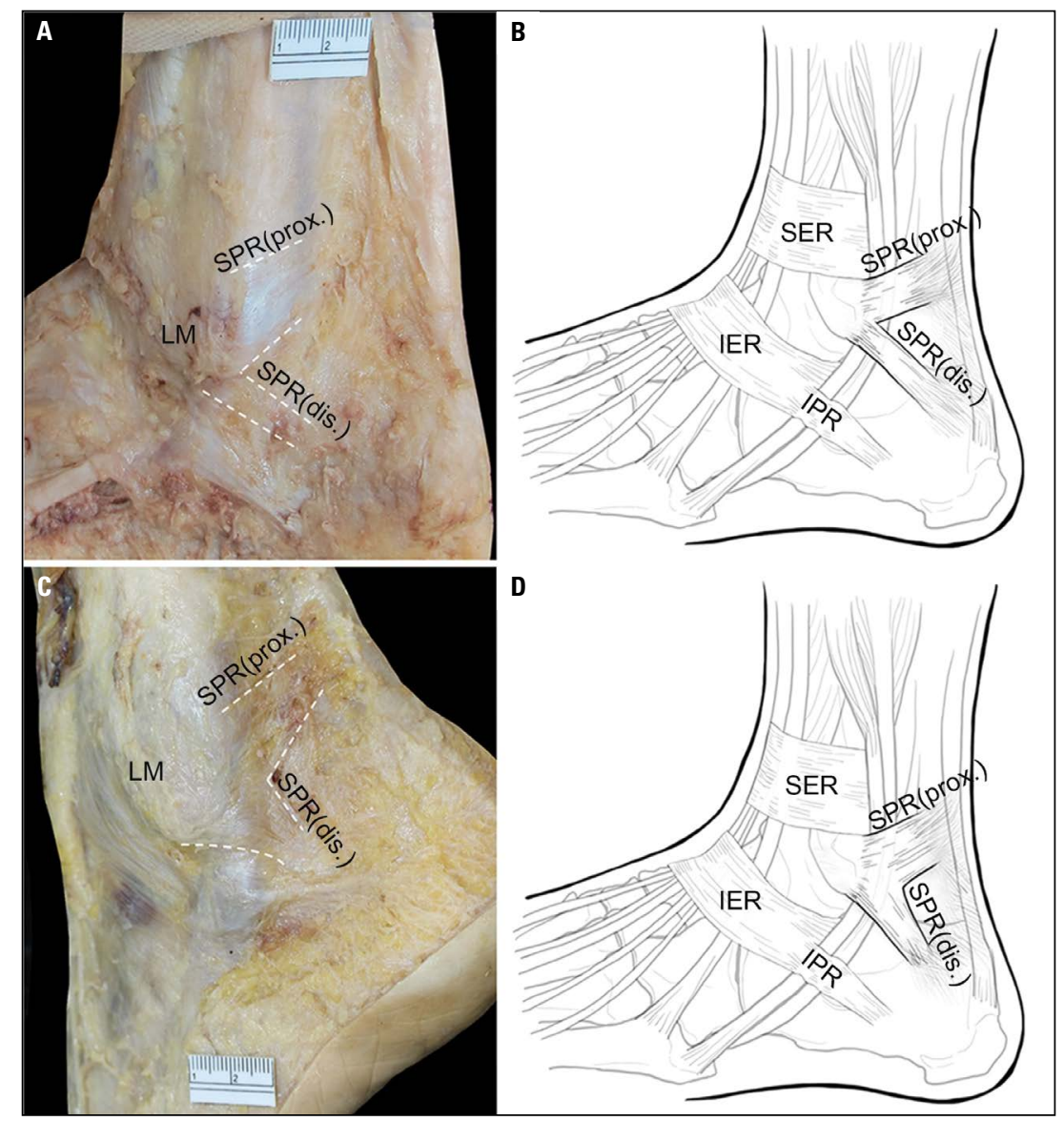

Figure 2. Photograph and illustration of type la (A, B) and $\mathrm{Ib}(\mathbf{C}, \mathbf{D})$ of superior peroneal retinaculum (SPR). Superior peroneal retinaculum proximal band [SPR (prox)] and superior peroneal retinaculum distal band [SPR (dis)] inserted on the posterior intermuscular septum and lateral wall of calcaneus; IER — inferior extensor retinaculum; IPR — inferior peroneal retinaculum; LM — lateral malleolus; SER — superior extensor retinaculum.

PB tendon tear was recorded. Each parameter was measured 3 times and the average was calculated. To ensure consistency, the same digital Vernier calliper and standard goniometer were used. All measurements were done by the same investigator.

\section{Statistical analysis}

Statistical analysis was performed by using IBM SPSS software version 22.0. The intra-class correlation coefficient (ICC) was used to determine the intra-tester reliability. Mean and standard deviation for each parameter were obtained. Shapiro-Wilk test of normality was used to determine the distribution of sample population. Unpaired t-test in normally distributed data and Mann-Whitney $U$ test in non-normally distributed data were used to compare parameters between genders and sides. One-way ANOVA (for parametric test) or Kruskal-Wallis (for nonparametric test) was used to compare the difference of the presence of PB tendon tear in each type.

\section{Ethical consideration}

This cadaveric study has been approved by the Institutional Review Board (IRB), Faculty of Medicine, Chulalongkorn University (IRB NO. 110/61).

\section{RESULTS}

\section{Characteristics, origin and the attachment of the SPR}

The SPR had a common origin which extended from the fibrocartilaginous ridge of the posterolateral surface of the lateral malleolus, but its insertion was varied. The SPR might be a single band or split into proximal and distal bands to insert on the posterior intermuscular septum and lateral wall of calcaneus. Direction of proximal band might be slightly upward or parallel to the horizontal axis. In this study, the SPR could be classified into three types according to their insertion patterns (Fig. 2-4). Type I consisted of double bands while type II and type III had single band. Details of the characteristic of each type are described 


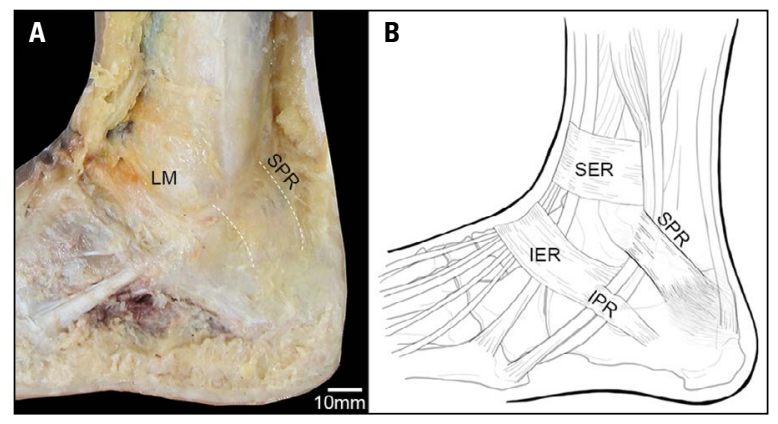

Figure 3. Photograph and illustration of type II (A, B) of superior peroneal retinaculum (SPR) with a single band inserted on lateral wall of the calcaneus; IER - inferior extensor retinaculum; IPR inferior peroneal retinaculum; LM — lateral malleolus; SER — superior extensor retinaculum.

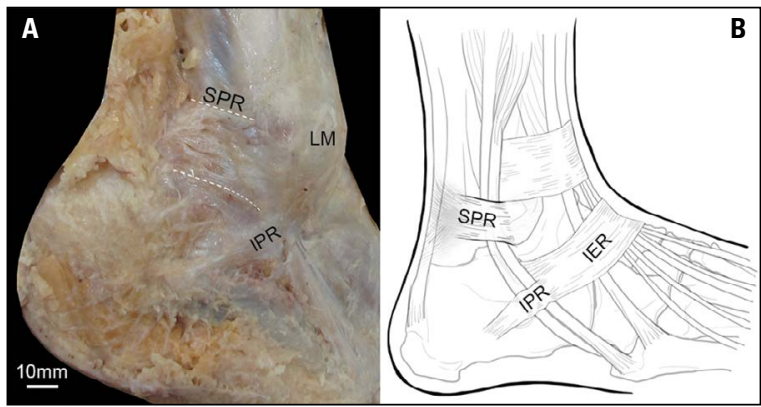

Figure 4. Photograph and illustration of type III (A, B) of superior peroneal retinaculum (SPR) with a single band inserted on posterior intermuscular septum; IER - inferior extensor retinaculum; IPR inferior peroneal retinaculum; LM — lateral malleolus; SER superior extensor retinaculum.

Table 1. Description of the types of superior peroneal retinaculum (SPR)

\begin{tabular}{|c|c|c|c|c|c|}
\hline \multicolumn{6}{|l|}{ Type } \\
\hline Type I & Type la & \multicolumn{4}{|c|}{$\begin{array}{r}\text { The SPR originated from fibrocartilaginous ridge } \\
\text { bands: the proximal band coursed slightly up } \\
\text { intermuscular se }\end{array}$} \\
\hline & Type lb & \multicolumn{4}{|c|}{$\begin{array}{l}\text { The SPR originated from fibrocartilaginous ridge of } \\
\text { two bands: the proximal coursed slightly upward or } \\
\text { insert on the posterior interm }\end{array}$} \\
\hline Type II & & \multicolumn{4}{|c|}{$\begin{array}{l}\text { The SPR originated from fibrocartilaginou } \\
\text { coursed slightly downwarc }\end{array}$} \\
\hline Type III & & \multicolumn{4}{|c|}{$\begin{array}{l}\text { The SPR originated from fibrocartilaginou } \\
\text { coursed slightly upward or parallel to the ho }\end{array}$} \\
\hline \multirow[t]{2}{*}{ Type } & \multirow[t]{2}{*}{ Total } & \multicolumn{2}{|c|}{ Left } & \multicolumn{2}{|c|}{ Right } \\
\hline & & Male & Female & Male & Female \\
\hline Type la & 14 (12.84\%) & 1 (0.92\%) & $6(5.50 \%)$ & $3(2.75 \%)$ & $4(3.67 \%)$ \\
\hline Type lb & $\begin{array}{c}48 \\
(44.04 \%)\end{array}$ & $\begin{array}{c}13 \\
(11.93 \%)\end{array}$ & $\begin{array}{c}12 \\
(11.01 \%)\end{array}$ & $\begin{array}{c}8 \\
(7.34 \%)\end{array}$ & $\begin{array}{c}15 \\
(13.76 \%)\end{array}$ \\
\hline Type II & $2(1.83 \%)$ & - & $2(1.83 \%)$ & - & - \\
\hline Type III & $\begin{array}{c}45 \\
(41.28 \%)\end{array}$ & $\begin{array}{c}14 \\
(12.84 \%)\end{array}$ & $\begin{array}{c}7 \\
(6.42 \%)\end{array}$ & $\begin{array}{c}16 \\
(14.68 \%)\end{array}$ & $\begin{array}{c}8 \\
(7.34 \%)\end{array}$ \\
\hline
\end{tabular}

in Table 1. However, type I could be divided into to two subtypes: type la and type lb based on the site of splitting into proximal and distal bands. The splitting site of type la was closed to its origin (Fig. 2A, B) while that of type lb was at its middle part (Fig. 2C, D). The prevalence of each type is shown in Table 2. The most common was type $\mathrm{lb}$ and the least common was type II. In addition, a symmetrical pattern was found in 29 (52.73\%) cadavers with a prevalence of $15(27.27 \%)$, $13(23.64 \%)$ and $1(1.82 \%)$ cadavers in type III, type Ib and type la, respectively. In cases of asymmetrical pattern, characteristic features found in the cadavers were type Ib with type III, type la with type Ib, type la with type III, type la with type II and type Ib with type II with a prevalence of $12(21.82 \%), 9(16.36 \%)$, $2(3.64 \%), 1(1.82 \%)$ and $1(1.82 \%)$, respectively. One cadaver with only one leg of type III was excluded from consideration of symmetrical pattern.

\section{The width of SPR}

Width of the SPR was obtained from its origin (Wo) and its insertion (Wi). The SPR had a common origin at the lateral malleolus with an average width of $18.37 \pm 4.13 \mathrm{~mm}$. The widest part of Wo was found in type lb. In contrast, the widest part of Wi was found in type III. In addition, the average of Wi of SPR inserted on the lateral calcaneus was lesser than those inserted on the lateral intermuscular septum (Table 3). Comparisons of the width of SPR between genders and sides in each type revealed that only the proximal and distal band of Wi of type la had a statistically significant difference between sides ( $p=0.018$ and 0.040 , respectively). 
Table 3. Width of the superior peroneal retinaculum (SPR) — mean \pm standard deviation (range) [mm]

\begin{tabular}{|c|c|c|c|c|c|}
\hline \multicolumn{2}{|l|}{ Type } & Width at origin & $\mathbf{P}$ & Width at insertion & $\mathbf{P}$ \\
\hline \multicolumn{6}{|l|}{ Type la } \\
\hline \multirow[t]{3}{*}{ Proximal band } & Left & $16.57 \pm 4.03(10.33-21.11)$ & 0.278 & $10.93 \pm 3.84(6.31-17.42)$ & $0.018^{*}$ \\
\hline & Right & $19.59 \pm 2.42(14.98-21.74)$ & & $16.25 \pm 3.47(11.38-21.70)$ & \\
\hline & Total & $17.58 \pm 3.36(10.33-21.74)$ & & $13.59 \pm 4.47(6.31-21.70)$ & \\
\hline \multirow[t]{3}{*}{ Distal band } & Left & NA & NA & $8.96 \pm 3.15(4.59-14.17)$ & $0.040^{*}$ \\
\hline & Right & NA & & $12.24 \pm 2.08(8.76-14.49)$ & \\
\hline & Total & NA & & $10.60 \pm 3.08(4.59-14.49)$ & \\
\hline \multicolumn{6}{|l|}{ Type lb } \\
\hline \multirow[t]{3}{*}{ Proximal band } & Left & $18.91 \pm 3.19(13.17-27.71)$ & 0.081 & $14.51 \pm 3.74$ (8.23-24.07) & 0.926 \\
\hline & Right & $20.23 \pm 3.45(15.37-28.98)$ & & $14.53 \pm 4.05(7.96-24.38)$ & \\
\hline & Total & $19.73 \pm 3.40$ (13.17-28.98) & & $14.52 \pm 3.85(7.96-24.38)$ & \\
\hline \multirow[t]{3}{*}{ Distal band } & Left & NA & NA & $10.22 \pm 4.25(5.65-29.94)$ & 0.556 \\
\hline & Right & NA & & $10.25 \pm 2.63(6.14-18.46)$ & \\
\hline & Total & NA & & $10.23 \pm 3.53(5.65-26.94)$ & \\
\hline \multicolumn{6}{|l|}{ Type ॥ } \\
\hline Single band & Left & $14.53 \pm 5.54(10.62-18.45)$ & NA & $10.83 \pm 7.00(5.88-15.78)$ & NA \\
\hline \multicolumn{6}{|l|}{ Type III } \\
\hline \multirow[t]{3}{*}{ Single band } & Left & $16.98 \pm 4.37(8.05-25.34)$ & 0.656 & $14.86 \pm 2.76(10.54-21.12)$ & 0.573 \\
\hline & Right & $17.61 \pm 4.97(10.81-26.22)$ & & $14.26 \pm 3.97(5.64-21.02)$ & \\
\hline & Total & $17.31 \pm 4.65(8.05-26.22)$ & & $14.55 \pm 3.42(5.64-21.12)$ & \\
\hline \multicolumn{6}{|c|}{ All cases of SPR based on insertion site } \\
\hline \multicolumn{2}{|c|}{ Posterior intermuscular septum } & & & $14.34 \pm 3.80(5.64-24.38)$ & \\
\hline \multicolumn{2}{|c|}{ Lateral wall of calcaneus } & & & $10.32 \pm 3.42(4.59-26.94)$ & \\
\hline
\end{tabular}

${ }^{*}$ Statistical significance; NA — not available

\section{The length of SPR}

Results of the length of SPR revealed that the mean length of those inserted on the posterior intermuscular septum and on the lateral wall of the calcaneus were $22.05 \pm 3.99$ and $28.41 \pm 5.49 \mathrm{~mm}$, respectively. The distal band of type lb was the longest, while type III was the shortest. Comparisons of the length of SPR between genders and sides revealed no statistically significant difference. Detail of morphometric data is tabulated in Table 4.

\section{The angle of SPR}

Results of the angle of the SPR revealed that most were acute angles, except those aligned parallel to the horizontal axis. The prevalence of parallel alignment of SPR was found in 1 and 4 cases of type Ib and type III, respectively. The mean upward angle of all type was $10.02 \pm 5.80$ degrees. All distal bands coursed downward to their insertion on the lateral border of calcaneus. The mean downward angle of all type was $40.75 \pm 18.98$ degrees. Details of the angle of SPR in each type are described in Table 4. Comparisons of the angle of SPR between genders and sides revealed no statistically significant difference.

\section{The thickness of the SPR}

The thickness of the SPR was measured at its middle part. The average thickness of both proximal and distal bands in all types was $0.47 \pm 0.20$ and $0.38 \pm 0.19 \mathrm{~mm}$, respectively. The thickest SPR was found in the proximal band of type III while the thinnest was found in the distal band of type lb. Comparisons of the thickness of SPR between genders and sides showed no statistically significant difference (Table. 4).

\section{Horizontal and vertical distances from the midpoint of origin and insertion of the SPR to the inferior tip of fibula}

In order to locate the precise attachment of the SPR, horizontal and vertical distances from the midpoint of the common origin and the insertion of the 
Table 4. Morphometric data of the superior peroneal retinaculum (SPR) - mean \pm standard deviation (range) [mm]

\begin{tabular}{|c|c|c|c|c|c|c|c|}
\hline \multicolumn{2}{|l|}{ Type } & Length & $\mathbf{P}$ & Thickness & $\mathbf{P}$ & Angle & $\mathbf{P}$ \\
\hline \multicolumn{8}{|l|}{ Type la } \\
\hline \multirow[t]{3}{*}{ Proximal band } & Left & $22.34 \pm 5.21(16.51-32.83)$ & 0.716 & $0.52 \pm 0.22(0.19-0.75)$ & 0.217 & $13.95 \pm 8.31(4.67-26.00)$ & 0.351 \\
\hline & Right & $23.39 \pm 5.26(16.70-32.35)$ & & $0.37 \pm 0.19(0.15-0.68)$ & & $10.48 \pm 4.55(3.33-14.67)$ & \\
\hline & Total & $22.86 \pm 5.06(16.51-32.83)$ & & $0.45 \pm 0.21(0.15-0.75)$ & & $12.21 \pm 6.69(3.33-26.00)$ & \\
\hline \multirow[t]{3}{*}{ Distal band } & Left & $22.55 \pm 5.56(16.27-32.72)$ & 0.381 & $0.54 \pm 0.23(0.27-0.82)$ & 0.291 & $34.57 \pm 18.47(6.67-59.33)$ & 0.332 \\
\hline & Right & $24.91 \pm 4.03(17.16-29.94)$ & & $0.43 \pm 0.16(0.24-0.64)$ & & $24.95 \pm 17.13(2.33-48.33)$ & \\
\hline & Total & $23.73 \pm 4.82(16.27-32.72)$ & & $0.49 \pm 0.20(0.24-0.82)$ & & $29.76 \pm 17.83(2.33-59.33)$ & \\
\hline \multicolumn{8}{|l|}{ Type lb } \\
\hline \multirow[t]{3}{*}{ Proximal band } & Left & $23.01 \pm 3.45(18.45-31.15)$ & 0.633 & $0.46 \pm 0.18(0.17-0.86)$ & 0.954 & $10.32 \pm 5.78(0.00-19.00)$ & 0.125 \\
\hline & Right & $22.57 \pm 2.93(16.24-27.76)$ & & $0.46 \pm 0.22(0.20-0.98)$ & & $8.13 \pm 3.58(3.67-19.33)$ & \\
\hline & Total & $22.80 \pm 3.18(16.24-31.15)$ & & $0.46 \pm 0.20(0.17-0.98)$ & & $9.27 \pm 4.92(0.00-19.33)$ & \\
\hline \multirow[t]{3}{*}{ Distal band } & Left & $28.79 \pm 4.71(22.38-40.71)$ & 0.073 & $0.29 \pm 0.15(0.08-0.63)$ & 0.180 & $43.72 \pm 15.36(10.67-73.33)$ & 0.910 \\
\hline & Right & $30.83 \pm 5.03(22.50-39.44)$ & & $0.37 \pm 0.19(0.11-0.78)$ & & $44.33 \pm 21.18(3.67-83.33)$ & \\
\hline & Total & $29.77 \pm 4.92(22.38-40.71)$ & & $0.33 \pm 0.17(0.08-0.78)$ & & $44.02 \pm 18.23(3.67-83.33)$ & \\
\hline \multicolumn{8}{|l|}{ Type ॥ } \\
\hline Single band & Left & $26.39 \pm 3.54(23.89-28.89)$ & NA & $0.73 \pm 0.25(0.55-0.91)$ & NA & $18.69 \pm 4.68(15.38-22.00)$ & NA \\
\hline \multicolumn{8}{|l|}{ Type III } \\
\hline \multirow[t]{3}{*}{ Single band } & Left & $20.30 \pm 3.09(15.68-26.60)$ & 0.438 & $0.49 \pm 0.22(0.14-0.93)$ & 0.707 & $10.27 \pm 5.40(0.00-18.33)$ & 0.609 \\
\hline & Right & $21.27 \pm 4.92(13.13-36.64)$ & & $0.46 \pm 0.17(0.22-0.76)$ & & $9.32 \pm 6.76(0.00-23.00)$ & \\
\hline & Total & $20.82 \pm 4.15(13.13-36.64)$ & & $0.47 \pm 0.20(0.14-0.93)$ & & $9.76 \pm 6.11(0.00-23.00)$ & \\
\hline \multicolumn{8}{|c|}{ All cases of SPR based on insertion site } \\
\hline \multicolumn{2}{|c|}{ Posterior intermuscular septum } & $22.05 \pm 3.99(13.13-36.64)$ & & $0.47 \pm 0.20(0.14-0.98)$ & & $10.02 \pm 5.80(0.00-26.00)$ & \\
\hline \multicolumn{2}{|c|}{ Lateral wall of calcaneus } & $28.41 \pm 5.49(16.27-40-71)$ & & $0.38 \pm 0.19(0.08-0.82)$ & & $40.75 \pm 18.98(2.33-83.33)$ & \\
\hline
\end{tabular}

NA - not available

SPR to the inferior tip of fibula were obtained. The midpoint of the origin was always above the fibular tip but the midpoint of insertion was varied with type. Since the proximal band of type I and the single band of type III inserted on the posterior intermuscular septum, the midpoint of insertion was always above the fibular tip. In contrast, the distal band of type la, Ib and II which inserted on the lateral wall of calcaneus was always below the fibular tip. The longest horizontal and vertical distances from midpoint of the origin were found in type la. The longest horizontal and vertical distance from midpoint of insertion was found in type la (Table 5). The X-coordinate represents the horizontal distance from the tip of fibula and the $Y$-coordinate represents the vertical distance from tip of fibula. The average coordinates $(X, Y)$ of origin in all types were $7.26 \pm 3.15(0.87-15.15)$ and $10.45 \pm$ $\pm 4.52(1.69-26.23) \mathrm{mm}$. The coordinates $(X, Y)$ of the insertion could be divided into two categories according to the insertion site. Average coordinates of SPR which inserted on the posterior intermuscular septum were $24.06 \pm 4.94$ and $13.35 \pm 5.18$, and those inserted on the lateral wall of calcaneus were $21.45 \pm 7.88$ and $13.59 \pm 6.73 \mathrm{~mm}$ (Table 5, Fig. 5). Comparisons of the horizontal and vertical distances from mid-point of origin and insertion to inferior tip of fibula between genders and sides showed that only vertical distance of type $\mathrm{lb}$ at its origin and vertical distance of type III at its insertion were significantly different between sides ( $p=0.003$ and 0.014 , respectively).

\section{The PB tendon tears}

After cutting the SPR at its origin, the superior peroneal tunnel (SP tunnel) was exposed. The contents of the SP tunnel are generally composed of the PB and $\mathrm{PL}$ tendons. The PL tendon lied superficial to the PB tendon. The PB tendon tear occurred in 14 from 109 (12.84\%) cases. They were found in SPR type Ib (10 cases), type III (3 cases) and type 2a (1 case). Moreover, one male cadaver with symmetrical SPR type Ib had bilateral PB tendon tears. The prevalence 
Table 5. Horizontal and vertical distances from mid-point of superior peroneal retinaculum (SPR) to the inferior tip of fibula — mean \pm standard deviation (range) [mm]

\begin{tabular}{|c|c|c|c|c|c|c|c|c|c|}
\hline \multirow[t]{2}{*}{ Type } & & \multicolumn{4}{|c|}{ Origin } & \multicolumn{4}{|c|}{ Insertion } \\
\hline & & $X$ axis & $\mathbf{P}$ & $Y$ axis & $\mathbf{P}$ & $\mathrm{X}$ axis & $\mathbf{P}$ & $Y$ axis & $\mathbf{P}$ \\
\hline \multicolumn{10}{|l|}{ Type la } \\
\hline \multirow[t]{3}{*}{ Proximal band } & Left & $\begin{array}{l}8.63 \pm 3.43 \\
(5.41-13.69)\end{array}$ & 0.849 & $\begin{array}{l}12.32 \pm 5.36 \\
(4.55-18.82)\end{array}$ & 0.058 & $\begin{array}{l}26.09 \pm 5.50 \\
(20.18-32.64)\end{array}$ & 0.879 & $\begin{array}{l}14.31 \pm 2.87 \\
(10.75-19.45)\end{array}$ & 0.152 \\
\hline & Right & $\begin{array}{l}9.02 \pm 4.00 \\
(2.62-15.15)\end{array}$ & & $\begin{array}{l}20.04 \pm 8.13 \\
(2.47-26.23)\end{array}$ & & $\begin{array}{l}25.62 \pm 5.87 \\
(15.02-32.52)\end{array}$ & & $\begin{array}{c}19.19 \pm 7.94 \\
(4.12-25.76)\end{array}$ & \\
\hline & Total & $\begin{array}{l}8.82 \pm 3.59 \\
(2.62-15.15)\end{array}$ & & $\begin{array}{l}16.18 \pm 7.73 \\
(2.47-26.23)\end{array}$ & & $\begin{array}{l}25.85 \pm 5.47 \\
(15.02-32.64)\end{array}$ & & $\begin{array}{l}16.75 \pm 6.27 \\
(4.12-25.76)\end{array}$ & \\
\hline \multirow[t]{3}{*}{ Distal band } & Left & NA & & NA & NA & $\begin{array}{r}22.94 \pm 8.00 \\
(14.90-35.14)\end{array}$ & 0.909 & $\begin{array}{c}14.48 \pm 4.64 \\
(7.20-22.38)\end{array}$ & 0.166 \\
\hline & Right & NA & & NA & & $\begin{array}{l}23.42 \pm 7.64 \\
(11.58-35.13)\end{array}$ & & $\begin{array}{l}10.11 \pm 6.32 \\
(1.53-20.03)\end{array}$ & \\
\hline & Total & NA & & NA & & $\begin{array}{c}23.18 \pm 7.52 \\
(11.58-35.14)\end{array}$ & & $\begin{array}{l}12.30 \pm 5.79 \\
(1.53-22.38)\end{array}$ & \\
\hline \multicolumn{10}{|l|}{ Type lb } \\
\hline \multirow[t]{3}{*}{ Proximal band } & Left & $\begin{array}{c}6.46 \pm 3.16 \\
(1.76-11.75)\end{array}$ & 0.749 & $\begin{array}{c}8.27 \pm 2.56 \\
(3.85-14.33)\end{array}$ & $0.003^{*}$ & $\begin{array}{c}23.27 \pm 5.80 \\
(10.46-35.67)\end{array}$ & 0.568 & $\begin{array}{c}12.54 \pm 4.39 \\
(4.24-21.44)\end{array}$ & 0.125 \\
\hline & Right & $\begin{array}{l}6.74 \pm 2.56 \\
(2.36-11.64)\end{array}$ & & $\begin{array}{l}10.70 \pm 2.77 \\
(4.21-15.98)\end{array}$ & & $\begin{array}{l}24.10 \pm 3.96 \\
(16.57-32.37)\end{array}$ & & $\begin{array}{l}14.68 \pm 5.07 \\
(5.32-22.64)\end{array}$ & \\
\hline & Total & $\begin{array}{c}6.59 \pm 2.86 \\
(1.76-11.75)\end{array}$ & & $\begin{array}{c}9.43 \pm 2.91 \\
(3.85-15.98)\end{array}$ & & $\begin{array}{c}23.67 \pm 4.97 \\
(10.46-35.67)\end{array}$ & & $\begin{array}{c}13.56 \pm \\
4.80(4.24-22.64)\end{array}$ & \\
\hline \multirow[t]{3}{*}{ Distal band } & Left & NA & NA & NA & NA & $\begin{array}{l}20.94 \pm 8.39 \\
(8.54-36.79)\end{array}$ & 0.439 & $\begin{array}{c}14.19 \pm 6.94 \\
(0.00-27.69)\end{array}$ & 0.824 \\
\hline & Right & NA & & NA & & $\begin{array}{c}20.95 \pm 7.70 \\
(11.17-38.66)\end{array}$ & & $\begin{array}{c}13.73 \pm 7.19 \\
(0.00-31.79)\end{array}$ & \\
\hline & Total & NA & & NA & & $\begin{array}{l}20.94 \pm 7.98 \\
(8.54-38.66)\end{array}$ & & $\begin{array}{c}13.97 \pm 6.99 \\
(0.00-31.79)\end{array}$ & \\
\hline \multicolumn{10}{|l|}{ Type II } \\
\hline Single band & Left & $\begin{array}{l}7.31 \pm 1.48 \\
(6.27-8.36)\end{array}$ & NA & $\begin{array}{c}9.13 \pm 5.13 \\
(5.51-12.76)\end{array}$ & NA & $\begin{array}{l}26.22 \pm 7.53 \\
(20.90-31.55)\end{array}$ & NA & $\begin{array}{c}4.48 \pm 2.48 \\
(2.73-6.24)\end{array}$ & NA \\
\hline \multicolumn{10}{|l|}{ Type III } \\
\hline \multirow[t]{3}{*}{ Single band } & Left & $\begin{array}{c}7.75 \pm 3.09 \\
(2.73-14.65)\end{array}$ & 0.587 & $\begin{array}{c}9.78 \pm 3.57 \\
(1.69-17.33)\end{array}$ & 0.988 & $\begin{array}{l}21.90 \pm 3.83 \\
(13.85-29.14)\end{array}$ & $0.014^{*}$ & $\begin{array}{l}12.27 \pm 5.37 \\
(1.06-20.34)\end{array}$ & 0.790 \\
\hline & Right & $\begin{array}{l}7.22 \pm 3.39 \\
(0.87-13.74)\end{array}$ & & $\begin{array}{c}9.79 \pm 3.02 \\
(4.62-17.28)\end{array}$ & & $\begin{array}{c}25.51 \pm 4.81 \\
(17.43-36.49)\end{array}$ & & $\begin{array}{c}12.64 \pm 4.00 \\
(3.12-18.37)\end{array}$ & \\
\hline & Total & $\begin{array}{c}7.47 \pm 3.22 \\
(0.87-14.65)\end{array}$ & & $\begin{array}{r}9.79 \pm 3.25 \\
(1.69-17.33)\end{array}$ & & $\begin{array}{l}23.82 \pm 4.70 \\
(13.85-36.49)\end{array}$ & & $\begin{array}{c}12.47 \pm 4.64 \\
(1.06-20.34)\end{array}$ & \\
\hline \multicolumn{10}{|c|}{ All cases of SPR based on insertion site } \\
\hline \multicolumn{2}{|c|}{ Posterior intermuscular septum } & $\begin{array}{c}7.26 \pm 3.15 \\
(0.87-15.15)\end{array}$ & & $\begin{array}{c}10.45 \pm 4.52 \\
(1.69-26.23)\end{array}$ & & $\begin{array}{l}24.06 \pm 4.94 \\
(10.46-36.49)\end{array}$ & & $\begin{array}{l}13.35 \pm 5.18 \\
(1.06-25.76)\end{array}$ & \\
\hline \multicolumn{2}{|c|}{ Lateral wall of calcaneus } & NA & & NA & & $\begin{array}{l}21.45 \pm 7.87 \\
(8.54-38.66)\end{array}$ & & $\begin{array}{l}13.59 \pm 6.73 \\
(0.00-31.79)\end{array}$ & \\
\hline
\end{tabular}

${ }^{*}$ Statistical significance; $\mathrm{X}$ axis — the horizontal distance; $\mathrm{Y}$ axis — the vertical distance; NA — not available

of the PB tendon tear in type $\mathrm{lb}$ was significantly higher than the others $(p=0.001)$. The extension of PB tendon tear was from above the lateral malleolus to the entrance of inferior peroneal tunnel in most cases. However, there were 2 cases of PB tendon tears extended from the retromalleolar groove to the inferior peroneal tunnel.

The intra-tester reliability on data extraction indicated good to excellent reliability $[\operatorname{ICC}(3,1)$ $=0.882-0.999]$. 


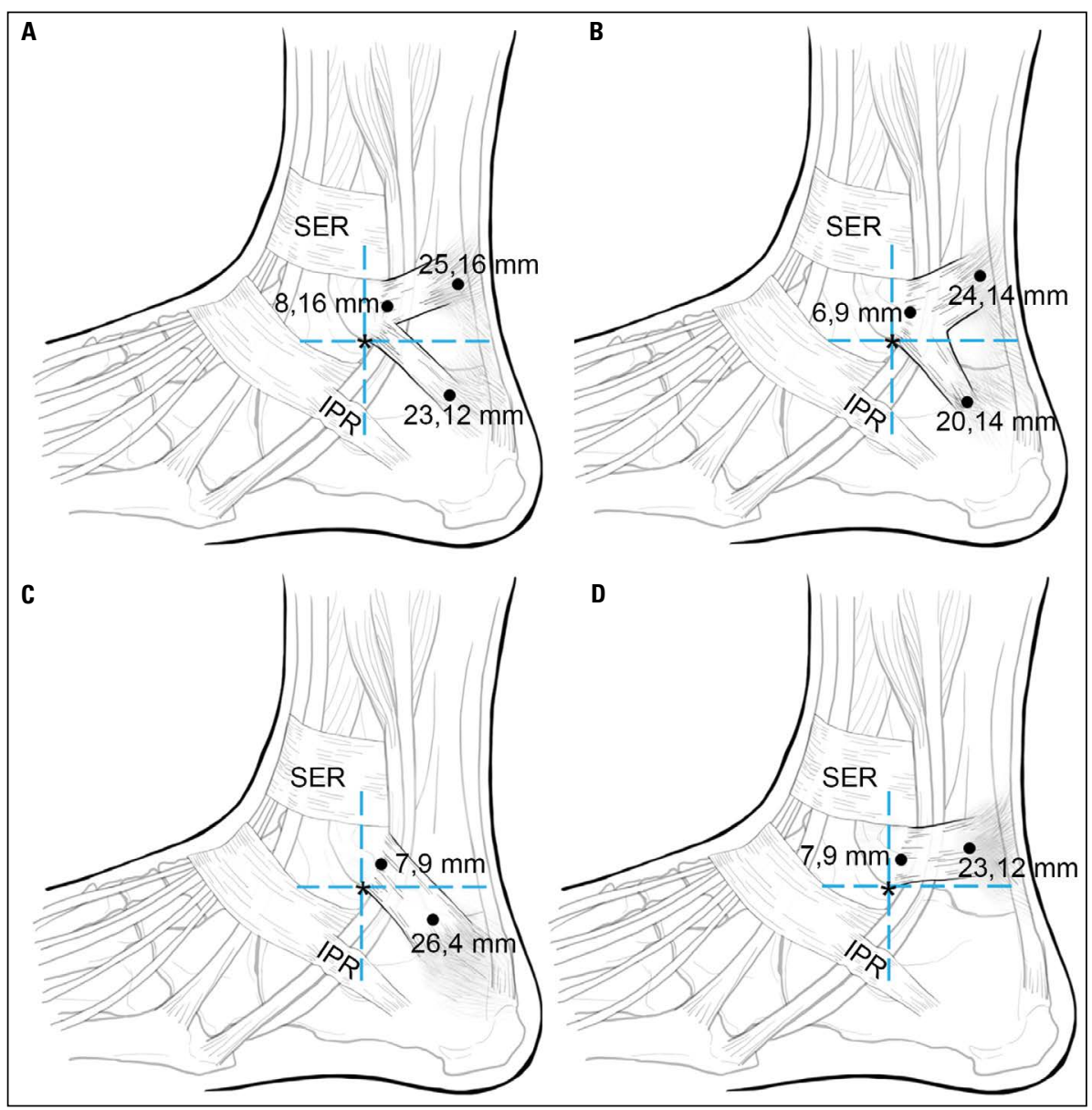

Figure 5. Illustrations of coordinates of mid-point of superior peroneal retinaculum (SPR) origin and insertion measured from the tip of fibula $\left({ }^{*}\right)$ in each type (X, Y axis); A. Type la; B. Type Ib; C. Type II; D. Type III; IPR — inferior peroneal retinaculum; SER — superior extensor retinaculum.

Table 6. Prevalence of peroneus brevis tendon tear and its association between types - N (\%)

\begin{tabular}{lccc}
\hline SPR & \multicolumn{2}{c}{ Peroneus brevis tendon tear } & P \\
\cline { 2 - 3 } & Present & Absent & \\
\hline Type la & $1(7.14 \%)$ & $13(92.86 \%)$ & $0.001^{*}$ \\
Type Ib & $10(20.83 \%)$ & $38(79.17 \%)$ & \\
Type III & $3(6.67 \%)$ & $42(93.33 \%)$ & \\
\hline
\end{tabular}

${ }^{*}$ Statistical significance; SPR — superior peroneal retinaculum

\section{DISCUSSION}

Morphology of the SPR has been described in standard textbook and previous reports $[2,6,15,21]$. The origin of SPR observed in this study was from the fibrocartilaginous ridge of the lateral malleolus with an extension to the distal tip of the fibula which was in accordance with previous studies $[2,6,15,21]$. The SPR had at least one insertion site either on the posterior intermuscular septum or lateral wall of the calcaneus. Insertion on the posterior intermuscular septum was in accordance with that described previously [21]. Moreover, magnetic resonance imaging (MRI) study also revealed that the horizontal band of the SPR attached to the superficial and deep aponeuroses of the posterior compartment of the lower portion of the leg [3]. However, we did not find insertion on the lateral border of the calcaneal tendon as reported by Davis et al., 1994 [6]. Hence, we divided the SPR based on the insertion pattern into three types; the double band of type I with subtype la and Ib, and the single band of type II and III. The difference between subtype la and $\mathrm{lb}$ was the site of splitting into proximal and distal band.

The average length of SPR inserted on the posterior intermuscular septum was approximately $23 \mathrm{~mm}$. However, the length of type III was shorter than others. The length of distal band was similar in both type la and lb. The average width of origin was in accordance with previous report [6]. Thickness of SPR 
reported in this study was lesser than previous study in MRI [16]. This might result from the difference in method and site of measurement.

The SPR plays an important role as the primary stabilizer of peroneal tendons to prevent the subluxation/dislocation $[5,18]$. Insufficiency of the SPR could cause symptomatic tendon instability and tendon injury afterwards $[5,7,24]$. The morphometric data showed that the site of splitting of type lb was in its middle part which was thinner than the rest. This would cause a decreasing in the strength of this retinaculum and resulted in SPR insufficiency. Furthermore, bilateral PB tendon tear was found in one case of symmetrical SPR type Ib. Taken together; the presence of type lb might have a potential to increase the risk of PB tendon tear.

There are several surgical procedures for treatment of peroneal tendon instability including the SPR repair or reconstruction, bone block procedures, and retromalleolar groove deepening $[4,5,7,13,18]$. Reconstruction of SPR using either autologous graft including gracilis tendon and plantaris tendon or allograft including tensor fascia latae has been reported $[9,14,20]$. Groove deepening is classically recommended in peroneal tendon instability with flat or convex retromalleolar groove contour. However, anatomical SPR reattachment without groove deepening is reported to be effective in any types of retromalleolar groove contour [4]. Morphometric data of SPR including its length, width and thickness provided in this study would be beneficial for surgical planning of graft type and harvesting in SPR reconstruction with autograft or allograft. The knowledge of coordinate of midpoint of SPR origin measured from the fibular tip would provide the precise area for attachment of repaired or reconstructed SPR on the lateral malleolus. Furthermore, the angle of the SPR and the coordinate of horizontal and vertical distance from midpoint of SPR insertion measured from fibular tip reported here can be used to design the direction and also specify the precise area for SPR reattachment on the lateral wall of calcaneus.

Superior peroneal retinaculum injury resulting in peroneal tendon instability can be associated with the calcaneal fracture, especially Sanders A type of calcaneus fracture [11, 12]. In this study, the SPR had at least one insertion site on the lateral wall of calcaneus, except type III. Type II of SPR inserted solely on the lateral wall of the calcaneus. Therefore, the SPR integrity and stability of peroneal tendon should always be evaluated in the treatment of calcaneal fractures.

\section{Limitations of the study}

Limitations of this study were the use of the formalin fixed cadaver which might affect the positions of the foot and ankle. Although the adjustment of the foot and ankle to the neutral position by Achilles tendon releasing and a supporting frame was performed, embalmed cadaveric legs might yield different results from fresh or soft-embalmed cadaveric legs.

\section{CONCLUSIONS}

Characteristics and morphometric data of the SPR were described. SPR could be divided by the insertion pattern into type la, type Ib, type II and type III. SPR had at least one insertion band on the posterior intermuscular septum or lateral wall of calcaneus. Morphometric data provided in this study are beneficial for SPR surgical procedures including reattachment and reconstruction. Moreover, type lb had a trend to be associated with PB tendon tear.

\section{Acknowledgements}

The authors sincerely thank to Dr. Somjet Tosamran and Ms. Amornrat Tothonglor in dissection and data collection. Special thanks to the technical staff members of the Department of Anatomy, Faculty of Medicine, Chulalongkorn University for their support in cadaveric care.

\section{REFERENCES}

1. Athavale SA, Gupta V, Kotgirwar S, et al. The peroneus quartus muscle: clinical correlation with evolutionary importance. Anat Sci Int. 2012; 87(2): 106-110, doi: 10.1007/ s12565-011-0129-3, indexed in Pubmed: 22252433.

2. Athavale SA, Swathi, Vangara SV. Anatomy of the superior peroneal tunnel. J Bone Joint Surg Am. 2011; 93(6): 564-571, doi: 10.2106/JBJS.J.00662, indexed in Pubmed: 21411707.

3. Cabral P, Paulino C, Takahashi R, et al. Correlation of morphologic and pathologic features of the various tendon groups around the ankle: MR imaging investigation. Skeletal Radiol. 2013; 42(10): 1393-1402, doi: 10.1007/ s00256-013-1650-3, indexed in Pubmed: 23820630.

4. Cho J, Kim JY, Song DG, et al. Comparison of outcome after retinaculum repair with and without fibular groove deepening for recurrent dislocation of the peroneal tendons. Foot Ankle Int. 2014; 35(7): 683-689, doi: 10.1177/1071100714531233, indexed in Pubmed: 24709746.

5. Coughlin MJ, Saltzman C, Anderson RB. Part VI arthritis, ostural disorders, and tendon disorders. Mann's surgery of the foot and ankle. 9th ed. Elsevier, Philadelphia 2014: 1232-1275. 
6. Davis WH, Sobel M, Deland J, et al. The superior peroneal retinaculum: an anatomic study. Foot Ankle Int. 1994; 15(5): 271-275, doi: 10.1177/107110079401500507, indexed in Pubmed: 7951966.

7. Dombek M, Lamm B, Saltrick K, et al. Peroneal tendon tears: a retrospective review. J Foot Ankle Surg. 2003; 42(5): 250-258, doi: 10.1016/s1067-2516(03)00314-4.

8. Eckert WR, Davis EA. Acute rupture of the peroneal retinaculum. J Bone Joint Surg. 1976; 58(5): 670-672, doi: 10.2106/00004623-197658050-00016.

9. Hansen BH. Reconstruction of the peroneal retinaculum using the plantaris tendon: a case report. Scand J Med Sci Sports. 1996; 6(6): 355-358, doi: 10.1111/j.16000838.1996.tb00107.x, indexed in Pubmed: 9046547.

10. Karlsson J, Wiger P. Longitudinal split of the peroneus brevis tendon and lateral ankle instability: treatment of concomitant lesions. J Aathl Train. 2002: 463-466, indexed in Pubmed: 12937568.

11. Ketz JP, Maceroli M, Shields E, et al. Peroneal tendon instability in intra-articular calcaneus fractures: a retrospective comparative study and a new surgical technique. J Orthop Trauma. 2016; 30(3): e82-e87, doi: 10.1097/BOT.0000000000000494, indexed in Pubmed: 26606603.

12. Kwaadu KY, Fleming JJ, Florek D. Superior peroneal retinacular injuries in calcaneal fractures. J Foot Ankle Surg. 2015; 54(3): 458-463, doi: 10.1053/j.jfas.2014.12.018, indexed in Pubmed: 25726126.

13. Maffulli N, Ferran NA, Oliva F, et al. Recurrent subluxation of the peroneal tendons. Am J Sports Med. 2006; 34(6): 986-992, doi: 10.1177/0363546505283275, indexed in Pubmed: 16452271.

14. Miyamoto W, Takao M, Komatu F, et al. Reconstruction of the superior peroneal retinaculum using an autologous gracilis tendon graft for chronic dislocation of the peroneal tendons accompanied by lateral instability of the ankle: technical note. Knee Surg Sports Traumatol Arthrosc. 2007; 15(4): 461-464, doi: 10.1007/s00167-006-0258-8, indexed in Pubmed: 17187275.

15. Moore KL, II AFD, Agur AMR. In: Taylor C, editor. Clinically oriented anatomy. 7th ed. Liincott Williams \& Wilkins, a Wolters Kluwer business 2014 : 591-610.

16. Numkarunarunrote N, Malik A, Aguiar RO, et al. Retinacula of the foot and ankle: MRI with anatomic corre- lation in cadavers. AJR Am J Roentgenol. 2007; 188(4): W348-W354, doi: 10.2214/AJR.05.1066, indexed in Pubmed: 17377003.

17. Oliva F, Saxena A, Ferran NA, Maffulli N. Peroneal Tendinoathy. In: Sorts Medicine and Arthroscoic Surgery of the Foot and Ankle. Palo Alto: Springer Dordrecht Heidelberg, New York London 2013: 187-212.

18. Roth JA, Taylor WC, Whalen J. Peroneal tendon subluxation: the other lateral ankle injury. Br J Sports Med. 2010; 44(14): 1047-1053, doi: 10.1136/bjsm.2008.057182, indexed in Pubmed: 19945971.

19. Saragas NP, Ferrao PN, Mayet Z, et al. Peroneal tendon dislocation/subluxation - Case series and review of the literature. Foot Ankle Surg. 2016; 22(2): 125-130, doi: 10.1016/j.fas.2015.06.002, indexed in Pubmed: 27301733.

20. Schade VL, Harsha W, Rodman C, et al. Peroneal tendon reconstruction and coverage for treatment of septic peroneal tenosynovitis: a devastating complication of lateral ankle ligament reconstruction with a tendon allograft. J Foot Ankle Surg. 2016; 55(2): 406-413, doi: 10.1053/j. jfas.2015.02.007, indexed in Pubmed: 26002675.

21. Tubbs RS. Pelvic girdle and lower limb. In: Standring S (ed). Gray's Anatomy: the anatomical basis of clinical ractice. 41 ed. Elsevier, London 2014: 1400-1417.

22. van Dijk PAD, Gianakos AL, Kerkhoffs GM, et al. Return to sports and clinical outcomes in patients treated for peroneal tendon dislocation: a systematic review. Knee Surg Sports Traumatol Arthrosc. 2016; 24(4): 1155-1164, doi: 10.1007/ s00167-015-3833-z, indexed in Pubmed: 26519186.

23. Wang XT, Rosenberg ZS, Mechlin MB, et al. Normal variants and diseases of the peroneal tendons and superior peroneal retinaculum: MR imaging features. Radiographics. 2005; 25(3): 587-602, doi: 10.1148/rg.253045123, indexed in Pubmed: 15888611.

24. Zammit J, Singh D. The peroneus quartus muscle. Anatomy and clinical relevance. J Bone Joint Surg Br. 2003; 85(8): 1134-1137, doi: 10.1302/0301-620x.85b8.13532, indexed in Pubmed: 14653594.

25. Zhenbo Z, Jin W, Haifeng G, et al. Sliding fibular graft repair for the treatment of recurrent peroneal subluxation. Foot Ankle Int. 2014; 35(5): 496-503, doi: 10.1177/1071100714523271, indexed in Pubmed: 24637656. 